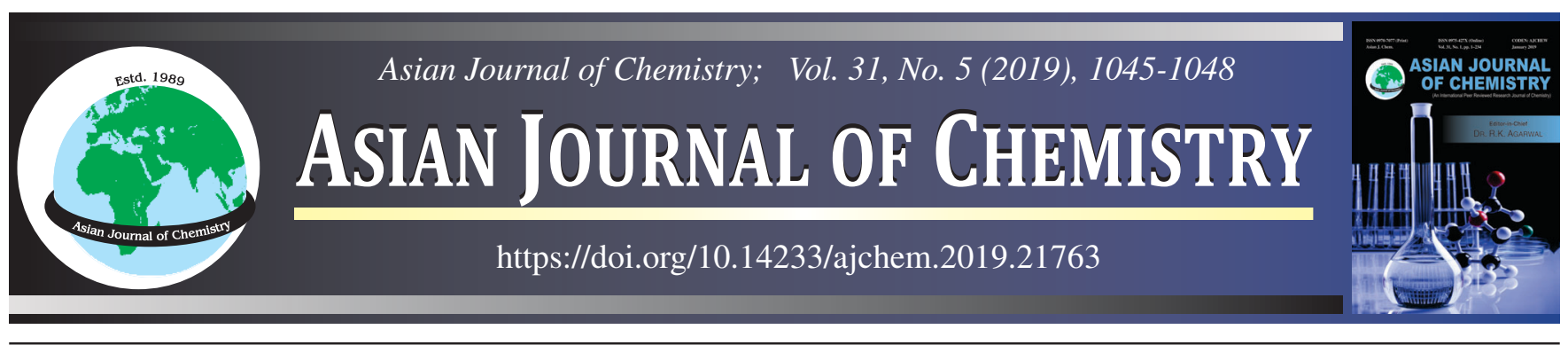

\title{
Box-Behnken Experimental Design for Extraction of Spinosin from Ziziphus mauritiana Lam. Seeds
}

Quang Thuong Tran ${ }^{1, *}$, Loan Thi Thanh Vu², Tram Huyen Le ${ }^{1}$, Ly Thi Phuong Giang $^{1}$ and Toyonobu Usuki ${ }^{3, *}$

${ }^{1}$ Department of Organic Chemistry, Hanoi University of Science and Technology, 1 Dai Co Viet Road, Hanoi, Vietnam

${ }^{2}$ Phu Tho Medical College, Truong Thinh, Phu Tho, Vietnam

${ }^{3}$ Department of Materials and Life Sciences, Faculty of Science and Technology, Sophia University, 7-1 Kioicho, Chiyoda-ku, Tokyo 102-8554, Japan

*Corresponding authors: E-mail: ttquang77ocd@ gmail.com; t-usuki@ sophia.ac.jp

Received: 15 October 2018;

Accepted: 14 December 2018;

Published online: 28 March 2019;

AJC-19328

The objective of this study was to evaluate the effects of extraction parameters (ethanol concentration, extraction ratio of solvent to raw material and extraction time) on the yield of spinosin from the seeds of Ziziphus mauritiana Lam. Box-Behnken factorial design was used in association with response surface methodology. The optimal extraction conditions were an ethanol concentration of $61 \%, 40$ (v/w) liquid-to-solid ratio, and $2.6 \mathrm{~h}$ extraction time with reflux. Spinosin was purified using Diaion HP20SS as an adsorbent. The maximum spinosin yield was $1.18 \mathrm{mg} / \mathrm{g}$ raw material. Present findings can be applied to future approaches for maximizing the extraction of spinosin from Z. mauritiana Lam. seeds.

Keywords: Box-Behnken design, Extraction, Spinosin, Ziziphus mauritiana Lam.

\section{INTRODUCTION}

The genus Ziziphus (Rhamnaceae) comprises approximately 170 species and 12 variants, and is distributed globally in warm-temperate and subtropical regions. Z. mauritiana Lam., an evergreen shrub up to $15 \mathrm{~m}$ in height, grows in Vietnam and throughout the low-latitudes of Asia, Africa and Australia $[1,2]$. The Vietnamese Pharmacopoeia states that the dry seeds of Z. mauritiana Lam. are used traditionally to tranquilize and relax the mind, sooth nerves (an anxiolytic effect), and reduce sweating (an anti-hydronic effect) [3]. The primary chemical compound of therapeutic interest is spinosin (Fig. 1) and is used for sedation and hypnosis. The hypnotic effect of spinosin has been assessed $[4,5]$. Spinosin significantly potentiates the hypnotic effect of pentobarbital by decreasing sleep latency, increasing sleep time, and increasing the rate of sleep onset induced by a sub-hypnotic dose of pentobarbital. Following the administration of a sub-hypnotic dose of pentobarbital, spinosin significantly increases the rate of sleep onset and exhibits a synergistic effect with 5-hydroxytryptophan (5-HTP) [6]. In addition, the potentiating effect of spinosin on pentobarbital<smiles>COc1cc2oc(-c3ccc(O)cc3)cc(=O)c2c(O)c1C1OC(CO)[C@@H](O)C(O)[C@H]1O[C@@H]1OC(CO)[C@@H](O)[C@H](O)[C@H]1O</smiles>

Fig. 1. Chemical structure of spinosin

induced hypnosis may be at least partially related to a postsynaptic 5-hydroxytryptamine (5-HT1A) receptor-dependent mechanism [7]. Jung et al. [8] reported that the spinosin ameliorates scopolamine-induced memory impairment in behavioral tasks such as the passive avoidance task in mice. Moreover, the memory-ameliorating effects of spinosinare mediated in part by the serotonergic neurotransmitter system, especially 5-HT1A receptor signaling. Additionally, spinosin increases the levels of phosphorylated extracellular signal-related kinases (ERK)

This is an open access journal, and articles are distributed under the terms of the Creative Commons Attribution-NonCommercial-ShareAlike 4.0 (CC BY-NC-SA 4.0) International License which allows readers to freely read, download, copy, distribute, print, search, or link to the full texts of its articles and to use them for any other lawful non-commercial purpose as long as the original source is duly acknowledged. 
and cAMP response element binding protein (CREB) in the hippocampus [8], and thus spinosin may be a potential therapeutic for the treatment of cognitive dysfunctions such as Alzheimer's disease. Ko et al. [9] reported that spinosin is effective against amyloid beta $(\mathrm{A} \beta)$-induced memory impairment. These memory-ameliorating effects arise from the anti-inflammatory and neuroprotective activities of spinosin.

Experiments designed for assessing and optimizing extraction processes maximize the amount of useful information obtained, require fewer experiments, and thus minimize costs and maximize the desired responses. Response surface methodology (RSM) is a useful statistical technique for constructing empirical models by employing the most important variables and their effects $[10,11]$. In this study, we optimized the extraction of spinosin from Ziziphus mauritiana Lam. seeds using RSM based on a Box-Behnken design (BBD), then we purified the crude spinosin by chromatography using Diaion HP20SS as an adsorbent.

\section{EXPERIMENTAL}

Ziziphus mauritiana seeds were purchased from a local market in Hanoi, Vietnam. Spinosin was purchased from $\mathrm{Si}$ Chuan Weikeqi Medical Technology Co., Ltd., Chengdu, China; purity $>98 \%$ ). Diaion HP20SS, methanol, HPLC water, ethanol and formic acid were purchased from Sigma Aldrich Co., Ltd. (St. Louis, USA).

Extraction procedure: Ziziphus mauritiana hulls were separated manually from Ziziphus mauritiana seeds ground into a powder using a high-speed disintegrator, and passed through a 60-mesh sieve. Fatty acids were removed by refluxing the powder twice with hexane and dichloromethane. Each pretreated sample (dried, powdered Ziziphus mauritiana hulls, $1 \mathrm{~g}$ ) in a $250 \mathrm{~mL}$ flat-bottom beaker was treated by refluxing with ethanol (65-95\%) an extraction ratio of solvent to raw material of $30-40 \mathrm{~mL} / \mathrm{g}$ and for an extraction time of $1-3 \mathrm{~h}$. The solvent was removed under reduced pressure at $55^{\circ} \mathrm{C}$ to give crude extracts, which were stored under refrigeration.

Response surface methodology (RSM) experimental design: Optimal spinosin performance was determined by applying the BOx-Behnken design (BBD) approach (Statease Design-Expert Software Version 7.0.0, Stat-Ease, Inc., Minneapolis, MN) to the following independent variables: ethanol concentration $(\% \mathrm{w} / \mathrm{w})$, extraction ratio of solvent to raw material $(\mathrm{mL} / \mathrm{g})$ and extraction time $(\mathrm{h})$. This design required 15 experiments, performed in random order to avoid any systematic error. Table-1 shows the factor, levels and experimental matrix for the BBD together with the respective responses for each run.

The values obtained using three variables [ethanol concentration $\left(\mathrm{X}_{1}\right)$, the ratio of water to raw material $\left(\mathrm{X}_{2}\right)$ and extraction time $\left(\mathrm{X}_{3}\right)$ ] and three levels, coded 1, 0 and -1 for high, intermediate and low level, respectively are shown in Table-1. The second order polynomial mode is as follows:

$$
\mathrm{Y}=\beta_{0}+\sum_{\mathrm{i}=1}^{3} \beta_{\mathrm{i}} \mathrm{X}_{\mathrm{i}}+\sum_{\mathrm{i}=1}^{3} \beta_{\mathrm{ij}} \mathrm{X}_{\mathrm{i}}^{2}+\sum_{\mathrm{i}=1}^{2} \sum_{\mathrm{j}=\mathrm{i}+1}^{3} \beta_{\mathrm{ij}} \mathrm{X}_{\mathrm{i}} \mathrm{X}_{\mathrm{j}} \text { (1) }
$$

where $Y$ is the predicted response (extraction yield of spinosin), $\beta_{0}, \beta_{\mathrm{i}}, \beta_{\mathrm{ii}}$ and $\beta_{\mathrm{ij}}$ are the regression coefficients for intercept, linear, quadratic and interaction terms, respectively, and $X_{i}$ and $X_{j}$ are the independent variables $(i \neq j)$.
TABLE-1

BBD MATRIX AND RESPONSE VALUES FOR THE EXTRACTION YIELDS OF SPINOSIN

\begin{tabular}{ccccc}
\hline Run & $\begin{array}{c}\text { Ethanol } \\
\text { concentration } \\
(\%)\end{array}$ & $\begin{array}{c}\text { Extraction ratio } \\
\text { of solvent to raw } \\
\text { material }(\mathrm{mL} / \mathrm{g})\end{array}$ & $\begin{array}{c}\text { Extraction } \\
\text { time }(\mathrm{h})\end{array}$ & $\begin{array}{c}\text { Spinosin } \\
(\mathrm{mg} / \mathrm{g})\end{array}$ \\
\hline 1 & 55 & 40 & 3 & 1.163 \\
2 & 70 & 35 & 1 & 0.875 \\
3 & 40 & 35 & 3 & 0.975 \\
4 & 70 & 35 & 3 & 1.068 \\
5 & 40 & 35 & 1 & 0.763 \\
6 & 70 & 40 & 2 & 1.130 \\
7 & 55 & 35 & 2 & 1.057 \\
8 & 70 & 30 & 2 & 0.708 \\
9 & 55 & 35 & 2 & 1.062 \\
10 & 40 & 40 & 2 & 0.967 \\
11 & 55 & 40 & 1 & 0.817 \\
12 & 55 & 35 & 2 & 1.054 \\
13 & 40 & 30 & 2 & 0.691 \\
14 & 55 & 30 & 3 & 0.793 \\
15 & 55 & 30 & 1 & 0.601 \\
\hline
\end{tabular}

Spinosin was assayed using an Agilent (Santa Clara, USA) series 1100 high performance liquid chromatography (HPLC) apparatus equipped with a G1315A diode array detector and an ODS-C18RP $(5 \mu \mathrm{m}, 150 \times 3.0 \mathrm{~mm})$ column maintained at $30^{\circ} \mathrm{C}$. The mobile phase $(0.4 \mathrm{~mL} / \mathrm{min})$ comprised methanol:0.1 $\%$ formic acid (v/v) and the gradient was 80:20 to 0:100 over $30 \mathrm{~min}$. The effluent was monitored at $254 \mathrm{~nm}$.

Preparation of sample and standard solutions: The samples were dissolved in $50 \mathrm{~mL}$ methanol, filtered, and then injected into the chromatography system. A standard stock solution was prepared and diluted in methanol to $0.01,0.1,0.2,0.4$ and 1.0 $\mathrm{mg} / \mathrm{mL}$ for constructing calibration curves. The spinosin concentrations were determined from the regression equation for the calibration curve $\left(\mathrm{y}=11000 \mathrm{x}+58, \mathrm{R}^{2}=0.99997\right)$.

Purification of spinosin: Powdered Ziziphus mauritiana hulls (100 g) was refluxed twice with hexane and dichloromethane to remove fatty acids, and then treated using the best conditions identified by the experimental design, filtered and the extract collected. The solvent was removed under reduced pressure at $55^{\circ} \mathrm{C}$ to give $12 \mathrm{~g}$ crude extract. The extract was dissolved in distilled water $(500 \mathrm{~mL})$, loaded onto a column $(2.5 \times$ $20 \mathrm{~cm}$ ) packed with Diaion HP20SS, then the column was washed with distilled water until the eluent was become colourless solution. The column was then eluted with water: methanol $=4: 1$ at a flow rate of $2.0 \mathrm{~mL} / \mathrm{min}$. The eluent was concentrated under reduced pressure to afford crude spinosin. The crude product was recrystallized from methanol to give $91 \mathrm{mg}$ of light yellow powder (spinosin). The structure of isolated spinosin was confirmed by $1 \mathrm{D}$ and 2D NMR measurements, which were performed by a Bruker AM 500 FT-NMR spectrometers with TMS as an internal standard. Mass spectrum was recorded on an Agilent 1200 series LC-MSD Ion Trap. MS $(\mathrm{m} / \mathrm{z})$ of spinosin was calculated for $\mathrm{C}_{28} \mathrm{H}_{31} \mathrm{O}_{15}[\mathrm{M}-\mathrm{H}]^{-}$607.2, found 607.1.

\section{RESULTS AND DISCUSSION}

\section{Single-factor experiments for the extraction of spinosin}

Effect of ethanol concentration on the extraction yield of spinosin: The concentration of ethanol used for extraction 
influences the efficiency of flavonoid extraction: a lower concentration of ethanol is generally suitable for the extraction of polar flavonoid compounds and a higher concentration for the extraction of non-polar flavonoid compounds. The effect of the concentration of ethanol on the extraction yield of spinosin is shown in Fig. 2A. Extraction was conducted using different concentrations of ethanol (25-85\%, v/v) while keeping the other extraction parameters constant (40:1 liquid-to-solid ratio, $2 \mathrm{~h}$ extraction time and reflux). The concentration of spinosin significantly increased from 0.62 to $1.05 \mathrm{mg}$ spinosin/g when the concentration of ethanol was increased from 25 to $55 \%$, then decreased at higher ethanol concentrations (e.g., 0.63 spinosin/g at $85 \%$ ethanol).

Effect of liquid-to-solid ratio on the yield of spinosin: The effect of liquid-to-solid ratio on the extraction yield of spinosin is shown in Fig. 2B. Extraction was conducted at different liquid-to-solid ratios $(20-40, \mathrm{v} / \mathrm{w})$ while keeping the other extraction parameters constant ( $55 \%$ ethanol, $2 \mathrm{~h}$ extraction time and reflux). The extraction yields of spinosin significantly increased from 0.52 to $1.04 \mathrm{mg}$ spinosin/g as liquid-to-solid ratio increased from 20 to 35 (v/w) due to the increased driving force for the mass transfer of spinosin. However, the extraction yields did not change significantly liquid-to-solid ratios above $35(\mathrm{v} / \mathrm{w})$.

Effect of extraction time on extraction yield of spinosin: Extraction time would significantly influence extraction efficiency for spinosin. The effect of different extraction times on the yields is shown in Fig. 2C. Extraction was conducted for different times while keeping the other extraction parameters constant (55\% ethanol, 35:1 liquid-to-solid ratio and reflux time). The concentration of spinosin significantly increased from 0.72 to $1.13 \mathrm{mg}$ spinosin/g when the extraction time was increased from 1 to $2 \mathrm{~h}$, whereas $3 \mathrm{~h}$ of the times lightly decreased the concentration of spinosinto 0.92 spinosin/g.

Optimization of the yield of spinosin: The single-factor experiments required 15 experiments to optimize the extraction conditions. The design matrix and corresponding results from the RSM experiments used to evaluate the three independent variables [ethanol concentration $\left(X_{1}\right)$, the ratio of water to raw material $\left(\mathrm{X}_{2}\right)$ and extraction time $\left(\mathrm{X}_{3}\right)$ ] are shown in Table-1. Application of multiple regression analysis to the experiment data provided the relationship between the response variables and the test variables using the following second-order polynomial equation:

$$
\begin{aligned}
\mathrm{Y}= & -6.47180+0.012944 \mathrm{X}_{1}+0.35452 \mathrm{X}_{2}+0.20163 \mathrm{X}_{3}+ \\
& 4.86667 \times 10^{-4} \mathrm{X}_{1} \mathrm{X}_{2}-3.16667 \times 10^{-4} \mathrm{X}_{1} \mathrm{X}_{3}+7.70000 \\
& \times 10^{-3} \mathrm{X}_{2} \mathrm{X}_{3}-2.3759 \times 10^{-4} \mathrm{X}_{1}{ }^{2}-5.20833 \times \\
& 10^{-3} \mathrm{X}_{2}{ }^{2}-0.083958 \mathrm{X}_{3}{ }^{2}
\end{aligned}
$$

The results of analysis of variance (ANOVA) are shown in Table-2. The Model F-value of 62.19 and the P-value of less than 0.001 indicated that the model was significant. Furthermore, $\mathrm{P}$-values of the linear coefficients $\left(\mathrm{X}_{1}, \mathrm{X}_{2}\right.$ and $\left.\mathrm{X}_{3}\right)$, the interaction term coefficients $\left(X_{1} X_{2}\right.$ and $\left.X_{2} X_{3}\right)$ and the quadratic term coefficients $\left(\mathrm{X}_{1}{ }^{2}, \mathrm{X}_{2}{ }^{2}\right.$ and $\left.\mathrm{X}_{3}{ }^{2}\right)$ were all lower than 0.05 , indicating the significant effects of these terms on extraction yield. Additionally, the determination coefficient $\left(\mathrm{R}^{2}\right)$ was 0.9911 , which indicated that only $0.89 \%$ of the total variations could not be explained by the model. The low coefficient of variation $(3.05 \%)$ suggested that the predicted and experi-

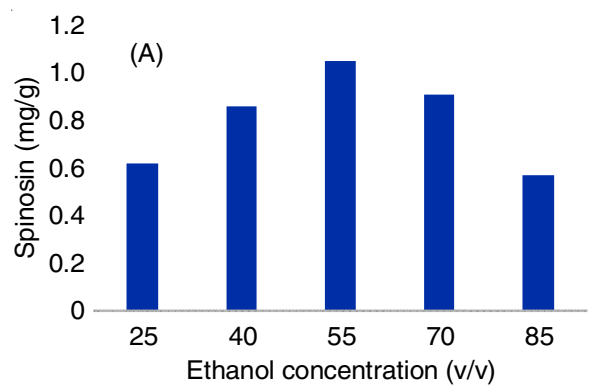

\begin{tabular}{|c|c|c|c|c|c|c|}
\hline \multicolumn{7}{|c|}{$\begin{array}{c}\text { TABLE-2 } \\
\text { ANOVA FOR THE RESPONSE SURFACE QUADRATIC MODEL FOR SPINOSIN EXTRACTION }\end{array}$} \\
\hline \multicolumn{7}{|c|}{ Analysis of variance table [Partial sum of squares - Type III] } \\
\hline Source & Sum of squares & df & Mean square & F value & p-value Prob > F & \\
\hline Model & 0.435459 & 9 & 0.048384 & 62.19199 & 0.0001 & Significant \\
\hline A-Ethanol & 0.018528 & 1 & 0.018528 & 23.81558 & 0.0046 & Significant \\
\hline B-Ratio & 0.206082 & 1 & 0.206082 & 264.8926 & $<0.0001$ & Significant \\
\hline C-time & 0.111156 & 1 & 0.111156 & 142.8773 & $<0.0001$ & Significant \\
\hline $\mathrm{AB}$ & 0.005329 & 1 & 0.005329 & 6.849761 & 0.0473 & Significant \\
\hline $\mathrm{AC}$ & $9.03 \times 10^{-5}$ & 1 & $9.03 \times 10^{-5}$ & 0.116005 & 0.7473 & - \\
\hline $\mathrm{BC}$ & 0.005929 & 1 & 0.005929 & 7.620986 & 0.0398 & Significant \\
\hline $\mathrm{A}^{2}$ & 0.010552 & 1 & 0.010552 & 13.56308 & 0.0143 & Significant \\
\hline $\mathrm{B}^{2}$ & 0.062600 & 1 & 0.062600 & 80.46465 & 0.0003 & Significant \\
\hline $\mathrm{C}^{2}$ & 0.026027 & 1 & 0.026027 & 33.45455 & 0.0022 & Significant \\
\hline Residual & 0.003890 & 5 & 0.000778 & - & - & - \\
\hline Lack of Fit & 0.003857 & 3 & 0.001286 & 78.71939 & 0.0126 & Significant \\
\hline Pure Error & $3.27 \times 10^{-5}$ & 2 & $1.63 \times 10^{-5}$ & - & - & - \\
\hline Cor Total & 0.439349 & 14 & - & - & - & - \\
\hline
\end{tabular}
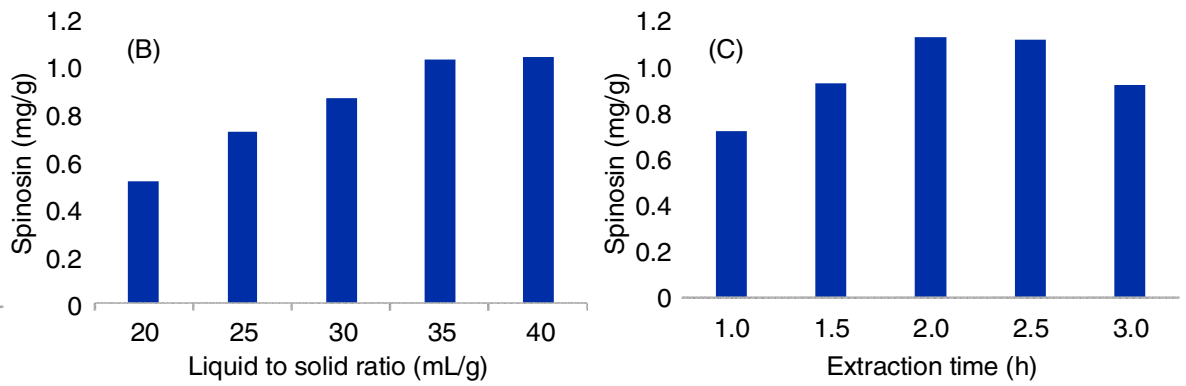

Fig. 2. Effects of extraction parameters on spinosin yield for (A) concentration of ethanol; (B) liquid to solid ratio; (C) extraction time 

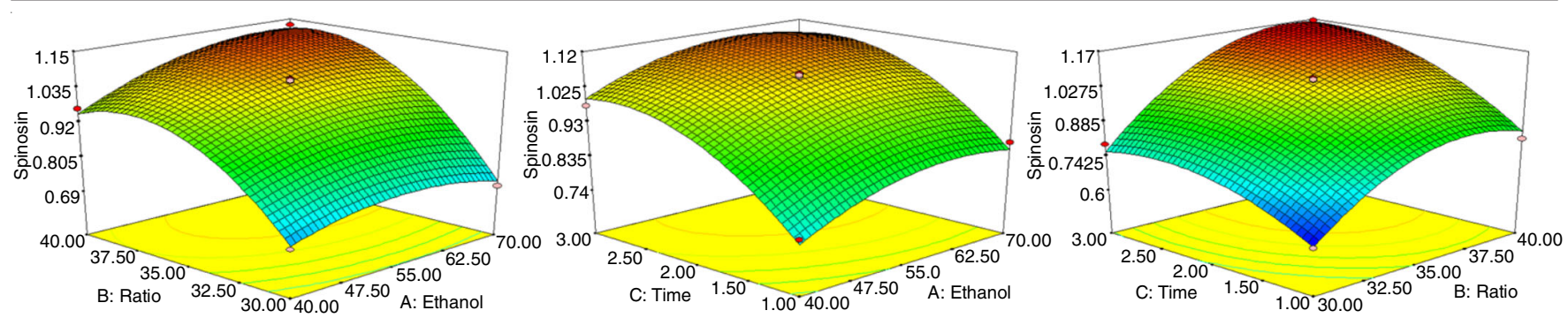

Fig. 3. Three-dimensional plotsforspinosin extraction

mental values were similar. 'Adeq Precision' was used to measure the signal to noise ratio and the value 24.447 indicated an adequate signal, suggesting the model could be used to navigate the design space.

Three-dimensional response surface plots are presented in Fig. 3. An increase in liquid-to-solid ratio $\left(\mathrm{X}_{2}\right)$ and extraction time $\left(\mathrm{X}_{3}\right)$ results in an increase in spinosin concentration to maximum levels, while an increase in ethanol concentration $\left(\mathrm{X}_{1}\right)$ results in an initial increase in spinosin concentration that then decreases at higher ethanol concentrations.

Optimal values of the selected variables were obtained by solving the regression eqn 2. Calculations using the DesignExpert software provided the values $X_{1}=61.72, X_{2}=39.78$ and $\mathrm{X}_{3}=2.65$, with the corresponding $\mathrm{Y}=1.18233 \mathrm{mg}$ spinosin/g. Using RSM, the optimal extraction conditions for spinosin were $61 \%$ ethanol for extraction, 40 (v/w) liquid-tosolid ratio, and $2.6 \mathrm{~h}$ extraction time with reflux. The actual experimentally obtained spinosin yield was $1.15 \pm 0.07 \mathrm{mg} / \mathrm{g}$, clearly demonstrating that the model fit the experimental data and therefore represented the optimized extraction procedure for spinosin from Z. mauritiana hulls.

Spinosin was optimally extracted from $100 \mathrm{~g}$ of powdered Z. mauritiana hulls and $91 \mathrm{mg}$ spinosin was isolated and purified using dianion HP20SS as an adsorbent.

\section{Conclusion}

Response surface methodology was used to optimize the extraction conditions for spinosin and the optimal extraction conditions were ethanol concentration $61.72 \%$, ratio of water to raw material $39.78: 1$, extraction time: $2.6 \mathrm{~h}$. Using these conditions, the extraction yield of spinosin was $1.15 \pm 0.07 \mathrm{mg} / \mathrm{g}$, in good agreement with the predicted value of $1.18 \mathrm{mg} / \mathrm{g}$. Spinosin was purified using Hiaion HP20SS as absorbent and $91 \mathrm{mg}$ spinosin was isolated from $100 \mathrm{~g}$ of powdered Z. mauritiana hulls.

\section{ACKNOWLEDGEMENTS}

This research was funded by the Vietnam National Foundation for Science and Technology Development (NAFOSTED) under grant number 104.01-2014.47.

\section{CONFLICT OF INTEREST}

The authors declare that there is no conflict of interests regarding the publication of this article.

\section{REFERENCES}

1. C.J. Ji, G.Z. Zeng, J. Han, W.J. He, Y.M. Zhang and N.H. Tan, Bioorg. Med. Chem. Lett., 22, 6377 (2012); https://doi.org/10.1016/j.bmcl.2012.08.074.

2. Y.L.Chen and B.K. Zhou, in Flora of China, Science Press: Beijing, vol. 48, pp. 131-146 (1982).

3. D.T. Loi, The Medicinal Plants and Herbs in Vietnam, Medical Publishing, Ha Noi: Vietnam, pp. 446-447 (2004).

4. K.H. Shin, C.K. Lee, W.S. Woo and S.S. Kang, Arch. Pharm. Res., 1, 7 (1978); https://doi.org/10.1007/BF02856299.

5. K. Kawashima, K. Saito, A. Yamada, S. Obara, T. Ozaki and Y. Kano, Biol. Pharm. Bull., 20, 1171 (1997); https://doi.org/10.1248/bpb.20.1171.

6. L.-E. Wang, Y.-J. Bai, X.-R. Shi, X.-Y. Cui, S.-Y. Cui, F. Zhang, Q.-Y. Zhang, Y.-Y. Zhao and Y.-H. Zhang, Pharmacol. Biochem. Behav., 90, 399 (2008); https://doi.org/10.1016/j.pbb.2008.03.022.

7. L.-E. Wang, X.-Y. Cui, S.-Y. Cui, J.-X. Cao, J. Zhang, Y.-H. Zhang, Q.-Y. Zhang, Y.-J. Bai and Y.-Y. Zhao, Phytomedicine, 17, 404 (2010); https://doi.org/10.1016/j.phymed.2010.01.014.

8. I.H. Jung, H.E. Lee, S.J. Park, Y.J. Ahn, G. Kwon, H. Woo, S.Y. Lee, J.S. Kim, Y.-W. Jo, D.S. Jang, S.S. Kang and J.H. Ryu, Pharmacol. Biochem. Behav., 120, 88 (2014);

https://doi.org/10.1016/j.pbb.2014.02.015.

9. S.Y. Ko, H.E. Lee, S.J. Park, S.J. Jeon, B. Kim, Q. Gao, D.S. Jang and H. Ryu, Biomol. Ther, 23, 156 (2015); https://doi.org/10.4062/biomolther.2014.110.

10. Z. Erbay and F. Icier, J. Food Eng., 91, 533 (2009); https://doi.org/10.1016/j.jfoodeng.2008.10.004.

11. B. Yang, X. Liu and Y.X. Gao, Innov. Food Sci. Emerg. Technol., 10, 610 (2009); https://doi.org/10.1016/j.ifset.2009.03.003. 